\title{
Investigation of Water Hammer Effect Through Pipeline System
}

\author{
Tan Wee Choon ${ }^{1}$, Lim Kheng Aik ${ }^{1}$, Lim Eng Aik ${ }^{2}$, Teoh Thean Hin ${ }^{3}$ \\ ${ }^{I}$ School of Mechatronic Engineering, Universiti Malaysia Perlis, Perlis, Malaysia \\ E-mail: tweechoon@unimap.edu.my,luc_0294@hotmail.com \\ ${ }^{2}$ Engineering Mathematics Institute, Universiti Malaysia Perlis, Perlis, Malaysia \\ E-mail:ealim@unimap.edu.my \\ ${ }^{3}$ Aircraft Maintenance Department, Politeknik Sultan Salahuddin Abdul Aziz Shah, Shah Alam, Malaysia \\ E-mail: tth9772@yahoo.com
}

\begin{abstract}
This paper we study the condition where the water hammer effect is occurs in pipe line. Water hammer can cause the pipe to break if the pressure is high enough. The experiment will be set-up to investigate the water hammer effect in order to avoid the water hammer effect happen. The prevention of water hammer effect will be propose and prove the prevention method is successfully reduce the water hammer effect. The prevention method using is installing the bypass pipe with non-return valve. The experiment is done by capture the vibration signal by using data acquisition device and accelerometer. The pressure signal is capture after a sudden shutoff for the valve. The signal is than analyze and convert to wave speed. The project is differentiating and compares the water hammer phenomenon with different pipe material, pipe length, inlet diameter of pipe, and pressure in pipeline. From the experiment, result shown that the lower strength material pipe, smaller inlet diameter pipe, and longer pipe will deal with lager water hammer effect. Besides, the prevention method by installing by pass pipe with non-return valve of water hammer effect is proved successfully reduce the water hammer phenomenon by $33.33 \%$ of pressure.
\end{abstract}

Keywords - Water hammer effect; Vibration; Prevention study

\section{INTRODUCTION}

This document is a template. Pressure surge or water hammer, as it is known, is the formation of pressure wave as a result of sudden change in liquid velocity in a piping system. The water hammer phenomena usually explained by considering by ideal reservoir pipe-valve system in which the steady flow with velocity $V_{o}$ is stopped by an instantaneous valve closure. In other say, it occurs when the fluid flow start or stop quickly or is forced to make a rapid change in direction, for example quick closing the valves and stoppage of a pump can create water hammer [1,2].

Hydraulic transient in close conduits have been a subject of both theoretical study and intense practical interest for more than one hundred years [1]. Unsteady fluid flows have been studied since man first bent water to his will. The ancient Chinese, the Mayan Indians of Central America, the Mesopotamian civilization bordering the Nile, Tigris, and Euphrates river systems, and many other societies throughout history have developed extensive systems for conveying water, primarily for purpose of irrigations, but also for domestic water supplies. With the arrival of the scientific age and the mathematical developments embodied in Newton's principia, the understanding of fluid flow took a quantum leap in terms of its theoretical abstraction. The advent of high-speed digital computers constituted another discrete transformation in the study and application of fluids engineering principles [1].

The first to successfully investigate the water hammer problem was the Italian engineer Lorenzo Allievi which water hammer can be analysed by two different approaches, rigid column theory which ignores compressibility of the fluid and elasticity of the walls of the pipe, of by full analysis including elasticity [3].

Water hammer effect is normally happening in daily life and only that people not realize it. A common example of a water hammer occurs in most homes everyday: Simply tuning off a shower quickly will send a loud thud through the house. Water hammer can cause pipeline to break if the pressure is high enough. Besides, when a valve in a pipe is closed, the water downstream of the valve will attempt to continue flowing, creating a vacuum that may cause the pipe to collapse or implode [4]. The effect of water hammer must be taken by analyse the situation where water hammer effect occur and propose a prevention of water hammer effect. 
Water hammer also happens in industry field. The industrial that commonly had use steam and water would found water hammer cases. Company like Shell is the company had used the steam as the power. Thus, engineer need to solve the effect of water hammer that happens in the steam pipe. It is very dangerous if the steam pipe is break.

\section{WATER HAMMER EFFECT}

\section{A. General Defination}

The earliest application of the one-dimensional wave equation to explain observed water hammer effects was made by Joukowsky in 1898 [4 - 8]. Joukowsky correctly predicted the maximum line pressures and disturbance propagation times in a water distribution system in which sudden valve closures occurred. Joukowsky's equation is expressed as:

$$
\Delta P=\rho a \Delta V
$$

$\Delta P$ is the pressure rise due to the water hammer $\left(\mathrm{N} / \mathrm{m}^{2}\right), a$ is the velocity of impulse waves $(\mathrm{m} / \mathrm{s}), \Delta V$ is the velocity change of liquid in the pipeline $(\mathrm{m} / \mathrm{s})$, and $\rho$ is the density of liquid $\left(\mathrm{kg} / \mathrm{m}^{3}\right)$. The relation can also be written as

$$
\Delta H=a \Delta V / g
$$

where $\Delta H$ is the pressure increase due to the water hammer in terms of column of water in meters and $g$ is the gravitational acceleration in $\mathrm{m} / \mathrm{s}^{2}$. In deriving the above equations the following assumptions were made: the friction losses are much smaller than the static pressure in the pipe, flow is single phase and there are no dissolved gases in the liquid, the liquid velocity change occurs in a time less than the critical time.

The speed of the pressure waves, $a$, is a function of the following parameters such as specific weight and elasticity module of the liquid, pipe diameter, wall thickness, and the distance between the support points, and The elasticity module of the pipe material.

The derived relation for calculating the pressure wave speed is as follows $[4,8]$ :

$$
a=\sqrt{\frac{1}{\left(\frac{\rho}{k}+\frac{D C_{1}}{E e}\right)}}
$$

Where $D$ is the pipe diameter, $e$ is the pipe wall thickness, $E$ is the elasticity modulus of the pipe material, $K$ is the elasticity module of the liquid, and $C_{l}$ is a constant that can be assumed to be equal to one.

\section{B. Parameters Affecting Water Hammer Effect}

Pressure waves in pipelines are generated due to different normal operations in the system such as opening and closing the valves, start up or shutting down the pumps, or any sudden change in the pump rotational speed $[8,9]$.

Generally, the sources that may affect the water hammer attenuation, shape and timing would be the pressure in pipe, velocity flow in pipe, and sudden change of velocity flow. However there is other sources that may affect the waveform predicted by classical water hammer theory include viscoelastic behavior of the pipe-wall material, blockage and leakage in addition to the unsteady friction, cavitations and fluid structure interaction. These discrepancies are based on the derivation of the water hammer equations for the liquid unsteady pipe flow [10].

\section{Prevention of Water Hammer Effect}

There are some methods can prevent water hammer effect. First, design the discharge pipe based on lower liquid velocities $[6,8,9]$. By decreasing the flow velocity, the effect of the water hammer will be minimized.

Besides, increasing the moment of inertia of the pump [8] can reduce the water hammer effect. Adding a flywheel on the rotating axis of the driving motor would prevent the rotational speed to reduce sharply and therefore restrain the excess pressure decrease or increase.

One of the simpler methods to prevent the damaging effects of the water hammer is to install a by-pass pipe with a non-return valve $[8,11]$. Under normal conditions, the non-return valve will close. However, after the shutdown of the pump, pressure will be decreased in the discharge pipe and once it becomes less than the suction pressure, the nonreturn valve will open and the liquid would enter to the discharge pipe thereby preventing more pressure reduction.

To prevent water hammer effect, it also can install surge tanks in piping system $[6,8,12]$. These tanks act as a reservoir to suppress the pressure waves and are installed on the discharge pipe. When the pressure in the pipe increases, liquid enters the tank and is stored there. During periods of subnormal pressure in the pipe, then, the liquid would flow back to the pipe, preventing rapid velocity changes.

One of the methods to control the water hammer is install air chambers $[6,8,13]$. Air chambers are basically a type of high pressure surge tanks which can be built in smaller sizes. In these tanks, the pressurized air locates on the top of liquid. The size of the chamber must be large enough to compensate the liquid in the subnormal pressure periods.

Besides that, by install a non-return valve also can control the water hammer effect $[6,8]$. The discharge pipes of the pumps are normally equipped with non-return valves. The main application of these valves is to prevent the flow running toward the pump when it stops, thereby reducing the adverse effects. During normal working conditions of the pump, the supply flow would keep the non-return valve open. Upon sudden stop of the pump, the flow rate would reduce rapidly until it reaches zero and would then flow back to the pump.

In addition, adding the pressure control valves would be one of good methods to reduce water hammer effect $[6,8]$. These valves are designed to open at very high pressures and are installed at the critical points of the piping system. During the pressure rise period, the valve would release liquid to the outside. This would reduce the pressure in the line and prevents any possible damages.

In other hand, it can also install the vacuum valves to the piping system [8]. These valves are installed on those points of the piping system in which there is a possibility of liquid evaporation due to subnormal pressures. When the pressure reduces beyond certain level in the pipe, these valves close and let the atmospheric air to enter the system. 


\section{METHODOLOGY}

In order to investigate the water hammer effect occurs in pipeline, below instrumentation and procedure being used.

\section{A. Instrumentation}

To investigate the water hammer effect, lab equipment tool that using is the LMS DAQ (use to read the vibration signal). The sensor using is accelerometer with sensitivity of $10.2 \mathrm{mV}$. Other apparatus are given in Table I.

TABLE I

APPARATUS OF EXPERIMENT

\begin{tabular}{|l|l|}
\hline Apparatus & Specifications \\
\hline \multirow{4}{*}{ Pump with Inverter } & 40 head meter, \\
& 3 phase pump, \\
& $240-415 \mathrm{~V}$, \\
& $0.64 \mathrm{k}$ watt power, \\
& $0.5 \mathrm{HP}$ \\
\hline \multirow{5}{*}{ Piping system } & $1 / 2$ inch pipe, \\
& $3 / 4$ inch pipe, \\
& 1 inch pipe \\
\hline \multirow{5}{*}{ Fitting } & $1 / 2$ inch connector, \\
& $3 / 4$ inch connector, \\
& 1 inch connector \\
\hline Surge tank & $1 \mathrm{~m}$ cube tank \\
\hline \multirow{2}{*}{ Valve } & $1 / 2$ inch Ball valve, \\
\hline \multirow{2}{*}{ Pressure gauge } & $3 / 4$ inch Ball valve \\
\hline
\end{tabular}

\section{B. Experimental Set Up}

An experiment is set up as Figure 1 to analysis the parameter that affects the water hammer effect. The parameter tested would be the area of pipe, material of pipe and the length of the pipe. The pipe with difference parameter would be installing at the tested area. Sensor of the LMS would put at the tested area and data would be collect by DAQ system. The FFT signal would be taking and the signal is calculated in the wave speed. The graph would be plot by the LMS DAQ system and by calculation of wave speed, the graph of wave speed versus the frequency also would be plot.

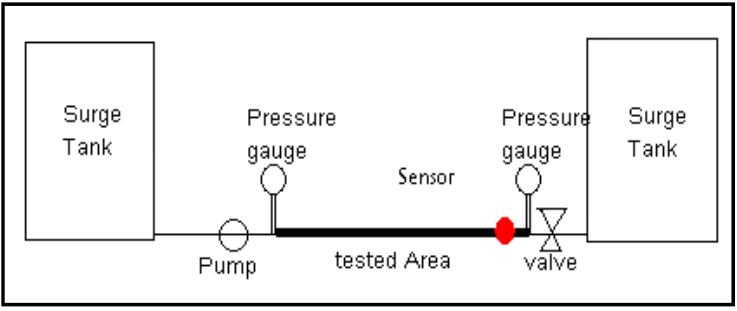

Fig. 1 Experiment set up for water hammer investigation

First, Set-up the experiment work bench base on the design. Before start experiment, the tested pipe is to be ensuring in the horizontal position by balancing fluid. The pump will be run for one period. During the pump running, make sure that there is no bubble effect in the pipe. After that, LMS data acquisition device is set-up. The accelerometer will be put at the tested area by wax. The result will be taken after a sudden close of the valve. The LMS data logger will read the vibration signal of pipe. The result of data will be taking for 3 times and the most suitable result will be chosen. Choose the signal that when water hammer effect is happen from data. Finally, analysis will be done after taking the signal.

The experiment step will be repeating for other parameter of experiment. Data of experiment will be save in the excel form. After finish the experiment, make sure that the electric supply of pump is turn off.

\section{Experimental Set Up for Prevention of Water Hammer Effect}

For the prevention method, the pipe is design to bypass valve with a non return valve [8] is installing to the pipe as shown in Figure 3.3. Install a by-pass pipe with a non-return valve is the one of the simpler methods to prevent the damaging effects of the water hammer. Under normal conditions, the pressure supplied by the pump would keep the non-return valve closed. However, after the shutdown of the pump, pressure will be decreased in the discharge pipe and once it becomes less than the suction pressure, the nonreturn valve will open and the liquid would enter from the suction pipe to the discharge pipe thereby preventing more pressure reduction.

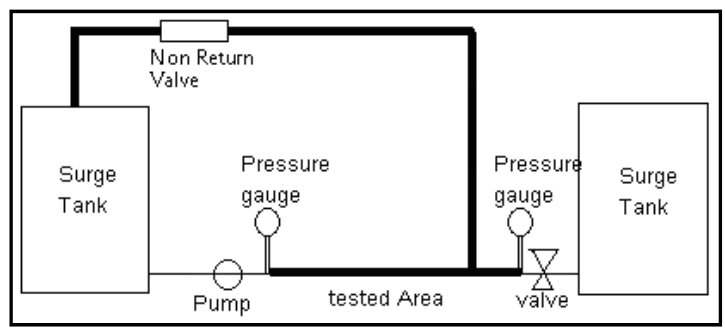

Fig. 2 Experiment set up for water hammer prevention investigation

\section{IV.DATA AND RESULTS}

From the experiment conducted, the results are given as follow:

\section{A. Effect of Pipe Length}

For this study parameter, two different pipe lengths which are 1.5 meter and 1 meter length $1 / 2$ inch PVC pipe being used as the specimens. The working pressure of the system is $2.5 \mathrm{psi}$. The results for amplitude pressure and wave speed are given in Figure 3 till Figure 6 respectively.

\section{B. Effect of Pipe Material}

For this study parameter, two different pipe material which are steel and PVC pipe of 1 meter length $3 / 4$ inch in diameter being considered. The working pressure of the system is 2.5 psi. The results for amplitude pressure and wave speed are given in Figure 7 till Figure 10 respectively.

\section{Effect of Working Pressure}

For this study parameter, two different ranges of working pressure which are $2.5 \mathrm{psi}$ and $2.2 \mathrm{psi}$ being consider. While the specimen is 1 meter length $3 / 4$ inch PVC pipe being considered. The results for amplitude pressure and wave speed are given in Figure 9 and Figure 12 respectively. 


\section{Prevention of Water Hammer Effect}

For this study, a non return valve is installing within the system. The specimen to be tested under this condition is the 1 meter length $1 / 2$ inch PVC pipe with working pressure of 2.5 psi being considered. The results for amplitude pressure and wave speed are given in Figure 13 and Figure 14 respectively.

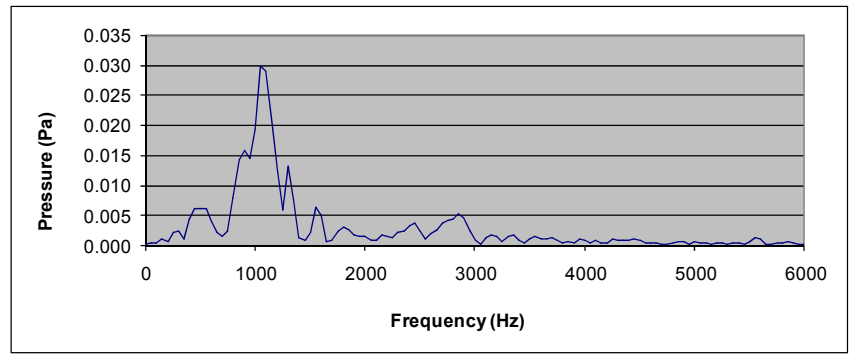

Fig. 3 Amplitude pressure of specimen 1.5 meter length $1 / 2$ inch PVC pipe for working pressure of $2.5 \mathrm{psi}$.

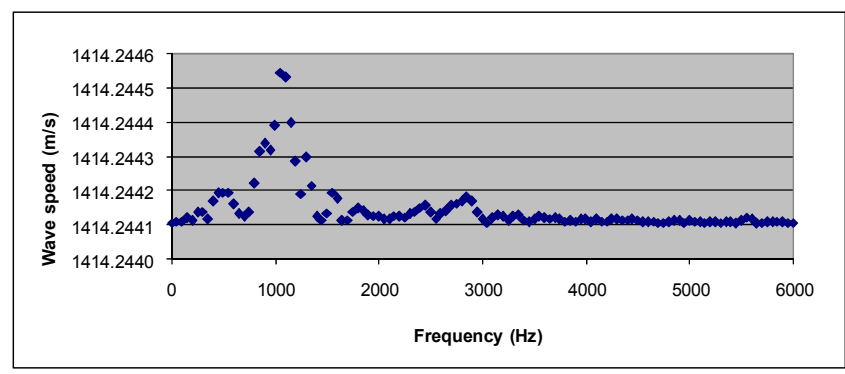

Fig. 4 Wave speed of specimen 1.5 meter length $1 / 2$ inch PVC pipe for working pressure of $2.5 \mathrm{psi}$.

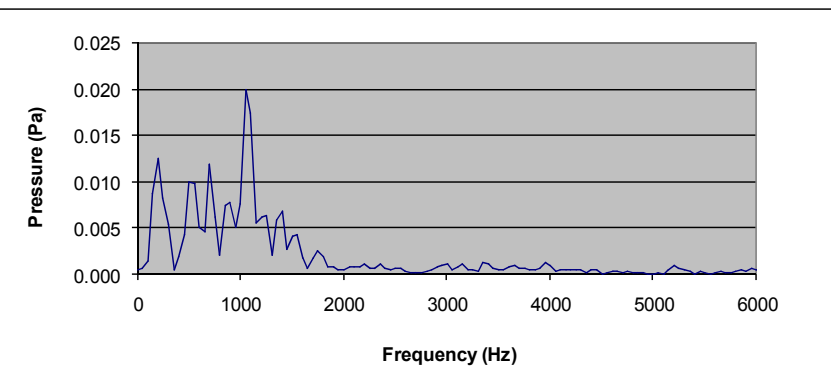

Fig. 5 Amplitude pressure of specimen 1 meter length $1 / 2$ inch PVC pipe for working pressure of $2.5 \mathrm{psi}$.

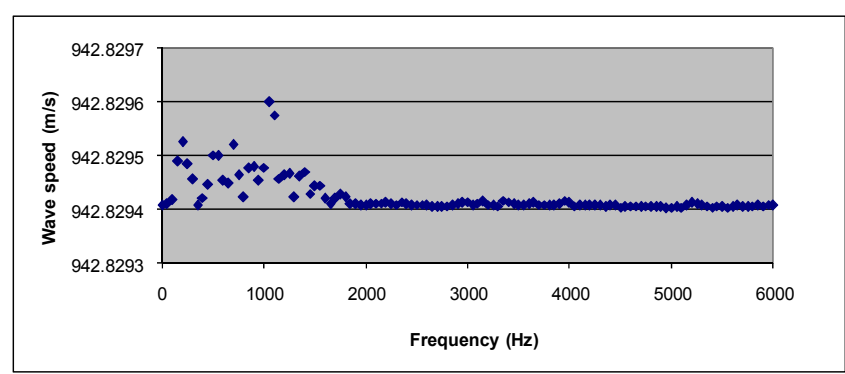

Fig. 6 Wave speed of specimen 1 meter length $1 \frac{1}{2}$ inch PVC pipe for working pressure of $2.5 \mathrm{psi}$.

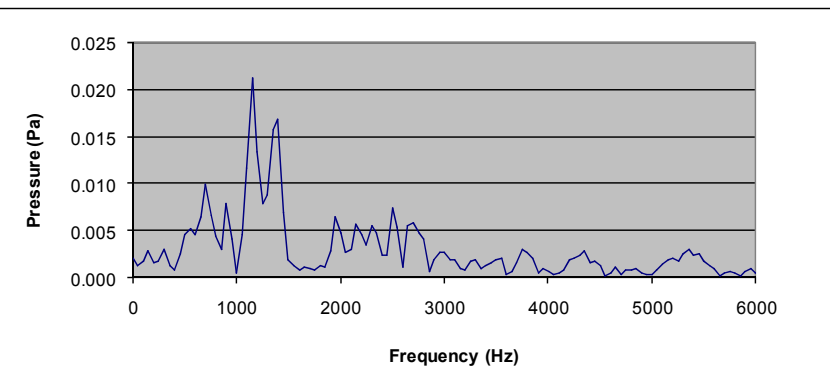

Fig. 7 Amplitude pressure of specimen 1 meter length $3 / 4$ inch Steel pipe for working pressure of $2.5 \mathrm{psi}$.

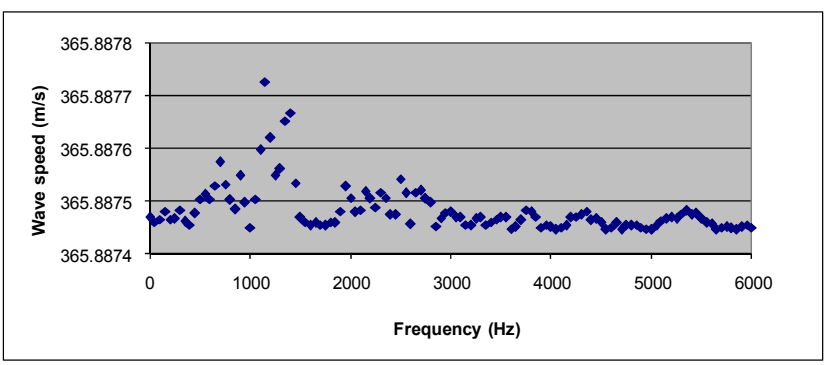

Fig. 8 Wave speed of specimen 1 meter length $3 / 4$ inch Steel pipe for working pressure of $2.5 \mathrm{psi}$.

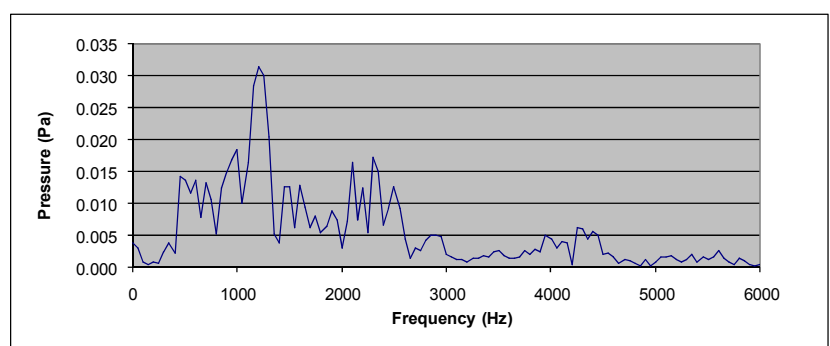

Fig. 9 Amplitude pressure of specimen 1 meter length $3 / 4$ inch PVC pipe for working pressure of $2.5 \mathrm{psi}$.

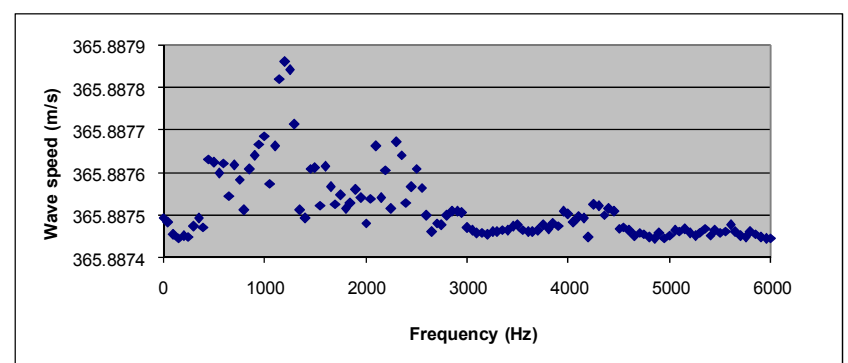

Fig. 10 Wave speed of specimen 1 meter length $3 / 4$ inch PVC pipe for working pressure of $2.5 \mathrm{psi}$.

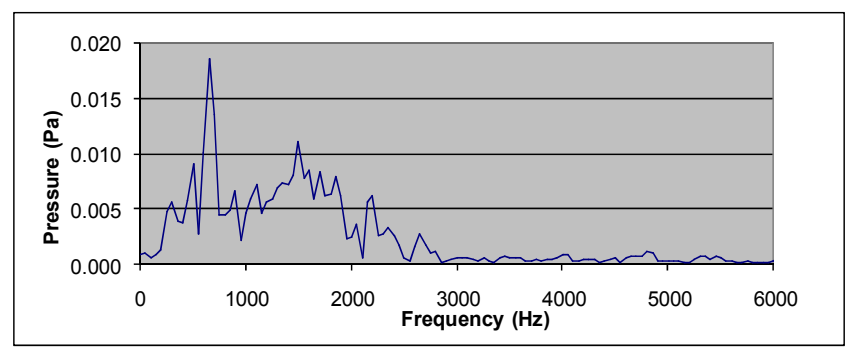

Fig. 11 Amplitude pressure of specimen 1 meter length $3 / 4$ inch PVC pipe for working pressure of $2.2 \mathrm{psi}$. 


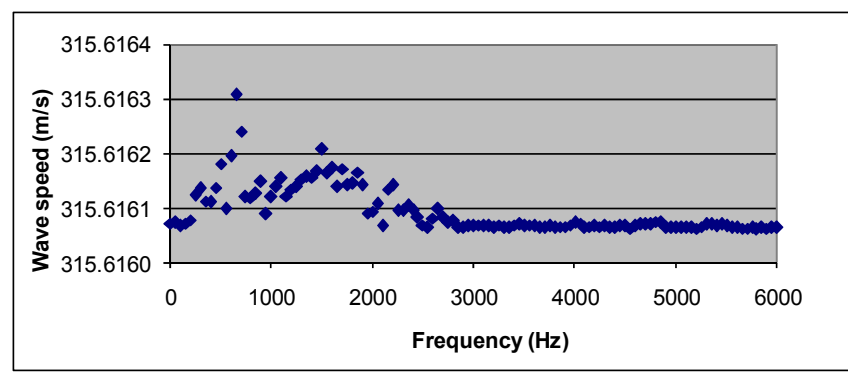

Fig. 12 Wave speed of specimen 1 meter length $3 / 4$ inch PVC pipe for working pressure of $2.2 \mathrm{psi}$.

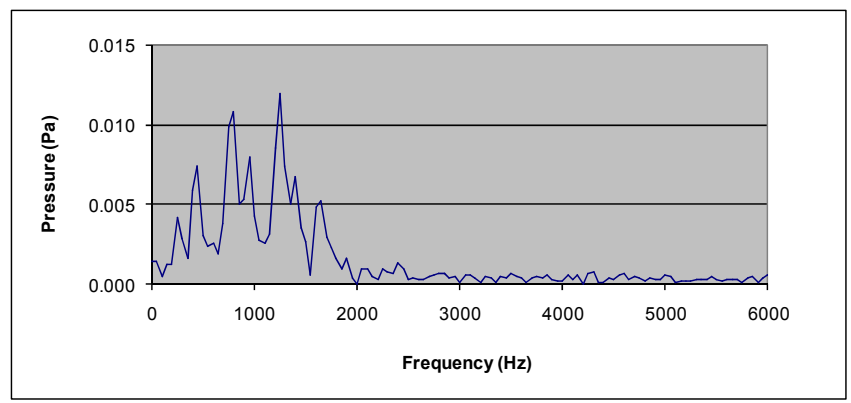

Fig. 13 Amplitude pressure of prevention study for specimen 1 meter length $1 / 2$ inch PVC pipe for working pressure of $2.5 \mathrm{psi}$.

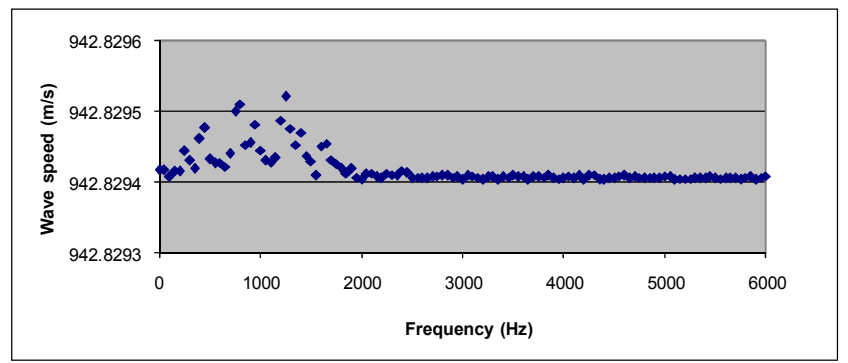

Fig. 14 Wave speed of prevention study for specimen 1 meter length $1 / 2$ inch PVC pipe for working pressure of 2.5 psi.

\section{WAVE SPEED}

In this paper, there are 6 specimens that are considered for investigation of water hammer effect. These specimens are including 1 meter length $3 / 4$ inch of PVC pipe, 1 meter length $3 / 4$ inch of steel pipe, 1 meter length $1 / 2$ inch of PVC pipe, and 1.5 meter length $1 / 2$ inch of PVC pipe. For 1 meter length $3 / 4$ inch PVC pipe, the data are taken in two different pressures. This is to compare the different pressure of water hammer effect. For 1 meter length $1 / 2$ inch of PVC pipe, the by-pass pipe with non-return valve is installed to reduce the water hammer effect.

For comparison of different diameter pipe for investigation of water hammer effect, the PVC pipe of $1 / 2$ inch and $3 / 4$ inch is installed for experiment work. Both experiments use the same level of pressure to conduct the experiment. From the experiment data result, 1 meter length $3 / 4$ inch PVC pipe have higher pressure compare to the 1 meter length $1 / 2$ inch PVC pipe. $3 / 4$ inch of PVC pipe has the maximum pressure of $0.031 \mathrm{~Pa}$ and $1 / 2$ inch of PVC pipe has the maximum pressure of $0.020 \mathrm{~Pa}$. The $3 / 4$ inch pipe deal with higher pressure compare to $1 / 2$ inch pipe when the valve is shut off suddenly. As a conclusion, the bigger diameter pipe occur more water hammer effect compare to smaller diameter pipe.
There are two types of pipe material that household using, there are steel pipe and PVC pipe. Hence, comparison between steel pipe and PVC pipe is done in this experiment. Both pipe using the same level of pressure and same diameter. From the experiment data, the PVC pipe deal with more water hammer effect compare to steel pipe. The maximum pressure of PVC pipe is $0.031 \mathrm{~Pa}$ and is higher than pressure of steel pipe which has pressure of $0.021 \mathrm{~Pa}$. This is due to the mechanical properties of the material pipe where steel has higher strength compare to PVC. As a summary, the steel pipe occur smaller water hammer effect compare to PVC pipe.

An experiment also compares the water hammer effect between the long pipe and shorter pipe. Both experiments are conduct under same diameter of pipe, same level of pressure and same material of pipe. The long pipe using is 1.5 meter and shorter pipe is 1 meter length. From the experiment, 1.5 meter length pipe deal with larger pressure compare with 1 meter length pipe. From the data, the 1.5 meter length pipe has the maximum pressure of $0.030 \mathrm{~Pa}$ and 1 meter length pipe has the maximum pressure of $0.020 \mathrm{~Pa}$. Therefore, it can be conclude that longer pipe occur more water hammer effect.

For comparison of different pressure, the experiment is done by using same pipe but different pressure setting by pump with inverter. As predicted, the higher pressure supply will due with larger water hammer effect in pipe. From experiment, the pipe with supply pressure of 2.5 psi has the maximum pressure signal of $0.031 \mathrm{~Pa}$ and the pressure supply of 2.2 psi has the maximum pressure signal of 0.018 $\mathrm{Pa}$. As a conclusion, higher pressure supply in pipe will create a greater water hammer effect compare with the smaller pressure supply in pipe.

In the experiment, there is installation of bypass pipe with non return valve for the prevention method. This method not $100 \%$ prevents the water hammer effect but it can reduce the water hammer effect. There are no ideal cases where there is no water hammer effect when sudden shut off the valve. From the experiment, the pressure in the pipe is reduce after apply the prevention method. Before install the bypass pipe with non-return valve, the maximum pressure signal is $0.020 \mathrm{~Pa}$. However, after applied the prevention method to the experiment system, the maximum pressure signal is $0.012 \mathrm{~Pa}$. The mean pressure is reducing about $33.33 \%$ where from $0.030 \mathrm{~Pa}$ reduces to $0.020 \mathrm{~Pa}$. This proves that the prevention method that suggested is success to reduce the water hammer effect.

\section{CONCLUSIONS}

The study of water hammer effect phenomena in the pipeline is very important for household usage and industry especially for industry which related to pipeline such as gas and oil industry and pipe manufacturing industry. The model experiment of water hammer effect is build in order to investigate the water hammer effect. From the study, it can be conclude that there are some parameters influencing water hammer phenomena. The obvious parameters are material of pipe and the pressure in the pipe.

The pipe material gives account into friction factor. The friction factor is most likely the parameter to determine the water hammer effect. From the result of the experiment, get 
that the water hammer effect in the PVC pipe is greater than the water hammer effect in steel pipe. Another important parameter that will affect the water hammer effect is the pressure in the pipe. The pressure in pipeline is directly influence by the initial velocity. From the experiment result, the high pressure pipeline occur more water hammer effect. This is due to the inverter pump is setting more initial velocity of fluid. Beside these 2 parameters, there are parameters like inlet diameter and length of the pipe also influence the water hammer effect.

The prevention method of water hammer effect which install the bypass pipe with non return valve had prove that the method is successfully to reduce the water hammer effect in the pipeline. From the experiment, the pressure in the pipe with prevention method is lower compare to the pipe that without prevention method. The mean pressure is reducing about $33.33 \%$ after installing the prevention method. This method is most useful in the household usage as the nonreturn valve is not an expensive item.

\section{NOMENCLATURE}

$a$
$C_{1}$
$D$
$e$
$E$
$g$
$\Delta H$
$K$
$\Delta P$
$V$
velocity of impulse waves

$\mathrm{ms}^{-1}$ constant pipe diameter pipe wall thickness

$\mathrm{m}$

$\mathrm{m}$ elasticity modulus of the pipe material $\mathrm{Nm}^{-2}$ gravitational acceleration $\mathrm{ms}^{-2}$ pressure head rise elasticity module of the liquid pressure rise due to the water hammer velocity

$\mathrm{m}$

$\mathrm{Nm}^{-2}$

$\mathrm{Nm}^{-2}$

$\mathrm{ms}^{-1}$

Greek letters

$\rho \quad$ density of liquid

$\mathrm{kgm}^{-3}$

\section{ACKNOWLEDGMENT}

Authors are grateful for the financial support from Universiti Malaysia Perlis (UniMAP) to conduct this research work.

\section{REFERENCES}

[1] C. K. Su, and C. Camara, "Cavitation luminescence in a water hammer: Upscaling sonoluminescence," Journal of Physics of Fluids, vol. 15, pp. 1457- 1461, 2003.

[2] D. J. Wood, "Water Hammer Analysis - Essential and Easy," Journal of Environment Engineering, vol. 131, pp. 1123- 1131, 2005.

[3] "Data Evaluation Report on PPP water hammer tests," Institut für Umwelt, UK.

[4] (2004) The LMNO Engineering Software Ltd. website. [Online]. Available: http:// www.lmnoeng.com /

[5] A. Bergant, A.R. Simpson, and A.S. Tijsseling, "Water Hammer with colum separation: His torical Review," Journal of Fluid and Structure, vol. 22, pp. 135- 171, 2005.

[6] "Water Hammer- Consultant Experience," Gugich \& Associates Pty Ltd, UK.

[7] M. Zhao, A. Mclnnis, and H. Axworthy, "A Review of the Water Hammer Theory and Practice," Journal of Applied Mechanic Review, vol. 58, pp. 49- 76, 2005.

[8] S. Nourbakhsh, B. Jaumotte, C. Hirsch and H. Parizi, Turbopumps \& Pumping systems: Part 2, Springer Berlin Heidelberg, UK, 2007.

[9] J. Fennel, Practical Solutions to Water Hammer, Revised Edition. Copper Development Centre Australia limited, Australia, 2000.

[10] A. Bergant, A. Tijsseling, and J. Vítkovský, Further investigation of Parameters affecting Water hammer wave attenuation, shape and timing - Part 1: Mathematical Tools, Eindhoven University of Technology, Netherlands, 2001.

[11] "A National Drinking Water Clearing House Fact Sheet," Tech Brief National Drinking Water Clearinghouse at West Virginia University, US.

[12] Boyle, Fluid Kinetics Water Hammer Solution, Fluid Kinetic surge arrestor article, Fluid Kinetic Corporation, Ventura, Carlifornia, 1996.

[13] A. Dudlik, H. M. Prasser, and S. Schlüter, Prevention of Water Hammer behind fast acting shut off, Fraunhofer UMSICHT, Oberhausen, 2005.
Subscripts

$o \quad$ instantaneous valve closure 